Volume 3 • Nomor 1 • Oktober 2019

Pege (Hal.) : $15-25$

(C) Universitas Pamulang

JL.Surya Kencana No.1 Pamulang, Tangerang Selatan - Banten

Telp. (021) 7412566, Fax (021) 7412491

website. :

Email : jurnalmarketing.unpam@gmail.com

\title{
Analisis SWOT Sebagai Perencanaan Desa Wisata Edukasi Agrikultur Cabe Dengan Pendekatan Konsep Pariwisata Berbasis Masyarakat di Desa Kabasiran, Parung Panjang, Kabupaten Bogor
}

\author{
Andriyani Hapsari ${ }^{1}$. Mutawali ${ }^{2}$ \\ Universitas Pamulang, email dosen01178@unpam.ac.id
}

\begin{abstract}
Abstrak. Penelitan ini bertujuan untuk menganalisis peran dan potensi perusahaan, masyarakat, serta stakeholder lainnya dalam mengembangkan Desa Wisata serta merekomendasikan rencana dan strategi pengelolaan Desa Wisata. Penelitian ini menggunakan pendekatan kualitatif dengan metodologi riset aksi partisipatif. Diharapkan setelah pelatihan ini diperoleh gambaran tentang kondisi sosial ekonomi masyarakat serta rekomendasi strategi pengembangan dan pengelolaan Desa Wisata. Dari hasil Analisis SWOT yang dilakukan dapat disimpulkan bahwa Desa Wisata Edukasi Agrikultur Cabe perlu menerapkan strategi diversifikasi, karena berada dalam wilayah kekuatan dan ancaman. Diversifikasi harus dilakukan sebanyak mungkin, agar konsep pengembangan wisata ini bisa dikenal di masyarakat. Perlu adanya pembuatan edukasi, tempat wisata yang nyaman, dan produk olahan cabe yang unik.
\end{abstract}

\section{Keywords: Analisis SWOT; Desa Wisata; Pariwisata Berbasis Komunitas.}

Abstract. This research aims to analyze the role and potential of the enterprise, the community, and other stakeholders in developing a Rural Tourism and recommend a Tourism Village management plan and strategy. This research uses a qualitative approach with a participatory action research methodology. It is expected that after this research an overview of the socioeconomic conditions of the community will be obtained as well as recommendations for a strategy for developing and managing a Rural Tourism. From the results of the SWOT analysis conducted, it can be concluded that the Rural Tourism needs to implement a diversification strategy, because it is in the area of strength and threat. Diversification must be done as much as possible, so that the concept of tourism development can be known in the community. It is necessary to make education, comfortable tourist attractions, and unique chilli processed products

Key words : SWOT Analysis; Rural Tourism; Community Based Tourism

\section{A. PENDAHULUAN}

Parung Panjang merupakan kecamatan yang letaknya paling jauh dari lbukota Kabupaten yaitu sekitar $87 \mathrm{Km}$. Terdiri dari 11 desa, yang salah satu desanya adalah Desa Kabasiran yang merupakan desa dengan wilayah terkecil yaitu $3,32 \mathrm{~km} 2$, dan berstatus desa perkotaan. Jumlah penduduk desa ini pada tahun 2016 sebesar 13.238 jiwa. Terdiri dari penduduk asli dan pendatang yang tinggal di perumahan-perumahan mulai dari perumahan sederhana hingga perumahan elit.. 
Jika dilihat dari Indeks Pembangunan Manusia, Kecamatan Parung Panjang berada di angka 71,29 dengan angka harapan hidup 71,40 harapan lama sekolah 10,93 dan rata-rata lama sekolah 7,18. Artinya untuk penduduk berusia 25 tahun ke atas rata-rata lama sekolah penduduk kecamatan ini adalah 7,18 tahun atau berhenti sampai pertengahan SMP. Sementara harapan lama sekolah untuk penduduk 7 tahun ke atas adalah 10,93 tahun. (https://bogorkab.bps.go.id) Hal ini sejalan dengan pengamatan penulis bahwa tingkat pendidikan penduduk asli di Desa Kabasiran masih rendah, yaitu mayoritas hanya lulusan SD. Hal ini berakibat pada mata pencahariannya yaitu menjadi buruh kasar dan buruh cuci gosok/ asisten rumah tangga bagi yang perempuan dengan gaji Rp. 400.000 - 500.000/ bulan. Disamping itu mata pencaharian lain di desa ini, warga di desa kabasiran sangat produktif, mereka sangat produktif dalam mencipatan barang yang memiliki nilai tinggi, seperti membuat roti, pempek, peyek, bon Cabe, susu murni, membuat asesoris perhiasan, menanam Cabe. Hasil dari olahan tersebut juga di jual, namun hasil penjualan nya tidak membantu perekonomian menjadi lebih baik karena keterbatasan pemasaran yang hanya dilakukan di satu komunitas.

Pembentukan desa wisata Cabe pada desa kebasiran parung panjang perlu dilakukan, karena telah memiliki potensi yang sangat baik dengan adanya Bu Evie sebagai salah satu tokoh masyarakat yang berhasil menciptakan anekan olahan unik dari Cabe, dan berhasil membina tokoh masyarakat di desa itu untuk terlibat dalam menanam Cabe dan melakukan produksi dari daerah itu. Di samping itu desa kabasiran juga memiliki wisata lain dan tidak ada konsep desa wisata Cabe, yaitu hanya wisata alam dengan adanya spot foto dan permainan lainnya di dalam wisata tersebut. Menurut Hasbullah Asyari dikuti dari Yohanes Sulistyadi (2019), kesuksesan desa wisata tercermin dari adanya dukungan dari seluruh anggota masyarakat, seperti kepala keluarga, ibu-ibu rumah tangga, pemuda, dan anak anak.

\section{B. KAJIAN LITERATUR}

\section{Analisis SWOT}

Menurut Istiqomah (2017), analisis SWOT merupakan bagian dari penilaian terhadap hasil identifikasi situasi, agar bisa menentukan suatu kondisi yang dikategorikan sebagai kekuatan, kelemahan, peluang atau ancaman. Analisis Swot merupakan bagian dari dari perencanaan hal utama yang harus dilakukan dalam proses perencanaan ini perlu mengenal kondisi saat ini dan perencanaan masa datang yang dapat memberi pengaruh dari proses tujuan institusi.

Matriks pada Tabel 1 terdapat dua bagian, IFAS (Internal Strategic Factors Analysis Summary) adalah ringkasan atau rumusan faktor strategis internal dalam kerangka kekuatan (Strenghts), dan kelemahan (Weakness). Sedangkan EFAS (External Strategic Factors Analysis Summary) adalah ringkasan atau rumusan faktor strategis eksternal dalam kerangka peluang (Opportunites), dan ancaman (Threat) (Istiqomah, 2017).

Tabel 1. Matriks SWOT dan kemungkinan strategi yang sesuai

\begin{tabular}{|c|c|c|}
\hline IFAS/EFAS & STRENGHTS (S) & WEAKNESSES (W) \\
\hline OPPORTUNITIES & Strategi SO & Strategi WO \\
\hline & $\begin{array}{l}\text { Menciptakan strategi yang } \\
\text { menggunakan kekuatan } \\
\text { untuk memanfaatkan } \\
\text { peluang. Digunakan jika }\end{array}$ & $\begin{array}{l}\text { Menciptakan strategi yang } \\
\text { meminimalkan kelemahan } \\
\text { untuk memanfaatkan } \\
\text { peluang. Digunakan jika }\end{array}$ \\
\hline
\end{tabular}




\begin{tabular}{|c|c|c|}
\hline & $\begin{array}{l}\text { perusahaan berada pada } \\
\text { kuadran I }\end{array}$ & $\begin{array}{l}\text { perusahaan berada pada } \\
\text { kuadran III }\end{array}$ \\
\hline THREATS (T) & $\begin{array}{l}\text { Strategi ST } \\
\text { Menciptakan strategi yang } \\
\text { menggunakan kekuatan } \\
\text { untuk } \\
\text { ancaman. Digunakan jika } \\
\text { perusahaan berada pada } \\
\text { kuadran II }\end{array}$ & $\begin{array}{l}\text { Strategi WT } \\
\text { Menciptakan strategi yang } \\
\text { meminimalkan kelemahan } \\
\text { dan menghindari } \\
\text { ancaman. Digunakan jika } \\
\text { perusahaan berada pada } \\
\text { kuadran IV }\end{array}$ \\
\hline
\end{tabular}

Sumber: Marimin (2004)

Dengan mengetahui posisi perusahaan pada kuadran yang tepat seperti pada Tabel 1, maka perusahaan dapat mengambil keputusan dengan lebih tepat, yaitu: (Marimin, 2004)

a. Jika posisi perusahaan berada pada kuadran I, menandakan bahwa situasi ini sangat menguntungkan, perusahaan memiliki peluang dan kekuatan, sehingga dapat memanfaatkan peluang yang ada. Strategi yang harus diterapkan adalah mendukung kebijakan pertumbuhan yang agresif.

b. Perusahaan yang berada pada kuadran II, berarti perusahaan menghadapi berbagai ancaman, perusahaan masih memiliki kekuatan internal. Strategi yang harus dilakukan menggunakan kekuatan untuk memanfaatkan peluang jangka panjang dengan cara diversifikasi.

c. Perusahaan yang berada pada kuadran III menunjukkan bahwa perusahaan mempunyai peluang yang sangat besar, tetapi di lain pihak perusahaan memiliki kelemahan internal. Fokus yang harus diambil oleh perusahaan adalah meminimalkan masalah-masalah internal perusahaan sehingga dapat merebut peluang pasar yang lebih baik.

d. Posisi perusahaan pada kuadran IV menunjukkan bahwa perusahaan menghadapi situasi yang sangat tidak menguntungkan, di mana selain perusahaan menghadapi berbagai ancaman juga menghadapi kelemahan internal.

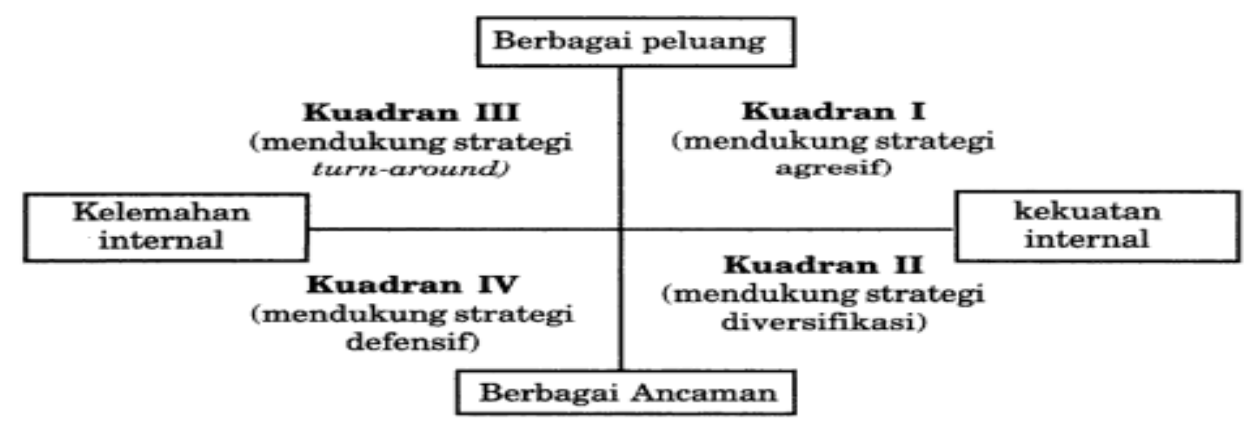

Gambar 2. Posisi Perusahaan pada berbagai Kondisi

Perencanaan

Perencanaan merupakan proses dasar dari manajemen untuk menentukan tujuan dan langkah-langkah untuk mencapai tujuan tersebut. Menurut Alam (2006 : 134) perencanaan memiliki beberapa manfaat yaitu, pertama perencanaan dapat membuat pelaksanaan tugas menjadi tepat dan kegiatan tiap unit akan terorganisir menuju arah yang sama. Kedua, perencanaan yang disusun berdasarkan penelitian yang akurat akan menghindarkan kesalahan-kesalahan yang mungkin terjadi. Ketiga, perencanaan memuat standar-standar atau batas-batas tindakan dan biaya sehingga memudahkan pelaksanaan pengawasan. Jurnal Pemasaran Kompetitif, Vol. 03, No. 1 / Oktober 2019 
Keempat, perencanaan dapat digunakan sebagai pedoman dalam melaksanakan kegiatan, sehingga aparat pelaksana memiliki irama atau gerak dan pandangan yang sama untuk mencapai tujuan.

Desa Wisata Edukasi Agrikultur Cabe

Berdasarkan Zebua (2016 : 36) yang mengutip penjelasan (Nuryanti : 1993), desa wisata merupakan suatu bentuk integrasi antara atraksi, akomodasi, dan fasilitas pendukung, yang disajikan dalam suatu struktur kehidupan masyarakat yang menyatu dengan tata cara dan tradisi yang berlaku. Ada dua konsep utama dalam komponen desa wisata yaitu pertama, akomodasi yang merupakan tempat tinggal penduduk setempat dan atau unit-unit yang berkembang atas konsep tempat tinggal penduduk, dan kedua, atraksi seluruh kehidupan keseharian penduduk setempat beserta setting fisik lokasi desa yang memungkinkan berintegrasinya wisatawan sebagai partisipasi aktif seperti kursus tari, kursus kerajinan khas daerah, bahasa dan lain-lain yang spesifik

Pariwisata Berbasis Masyarakat (Community Based Tourism)

Pariwisata berbasis masyarakat (community based tourism) merupakan suatu pendekatan pemberdayaan ekonomi masyarakat melalui sektor pariwisata. Secara singkat pariwisata berbasis masyarakat merupakan pelibatan masyarakat local pada proses perencanaan, pelaksanaan, dan pengawasan program-program pariwisata. Pelibatan dalam tiap tahapan ini penting, sehingga masyarakat tidak hanya menunggu, berharap memperoleh hasil keuntungan di akhirnya saja melainkan juga terlibat langsung dalam pemeliharaan serta pengembangan pariwisata. Pendekatan pariwisata berbasis masyarakat ini sangat berbeda dengan pengembangan pariwisata yang semata-mata berorientasi profit bagi investor.

\section{METODOLOGI PENELITIAN}

Metode yang digunakan untuk penelitian riset aksi partisipatif dengan pendekatan deskriptif kualitatif, dimana peneliti menggammbarkan dan menjelaskan situasi dan kondisi yang terjadi, setelah peneliti melakukan observasi dan wawancara berkatian dengan rencana pengembangan desa wisata edukasi agrikultur cabe.

Lokasi penelitian pada penelitian ini adalah Desa Kabasiran, Kecamatan Parung Panjang Kabupaten Bogor. Tepatnya di lingkungan sekitar lokasi PT Evia Maju Bersama, Jl. Dago Raya Km. 02 Kabasiran, Parung Panjang, Bogor 16360. Pengumpulan data penelitian ini berupa wawancara mendalam (depth interview) dan observasi dengan atau terhadap subjek penelitian yang terpilih. Penelitian ini juga akan didukung oleh foto-foto atau dokumentasi.

\section{HASIL DAN PEMBAHASAN}

Desa Kabasiran juga sudah dikenal oleh media, karena memiliki olahan cabe yang unik, kreatif dan inovatif dan mendapatkan penghargaan terbaik dari kesuksesan menjadi pengusaha produksi cabe yang paling inonvatif. Tidak hanya itu, dari tingkat pemerintah di sana juga memberikan antusias terhadap pertumbuhan ekonomi dari hasil kegiatan di Desa Kabasiran atas kegiatan menanam dan mengolah cabe yang bisa terjual hingga ke luar negeri.

Analisis SWOT UMKM Wisata Desa Cabe Parung Panjang

Analisis ini akan peneliti indentifikasikan menjadi dikategorikan sebagai kekuatan, kelemahan, peluang atau ancaman.

a. Kekuatan (Strength), merupakan situasi dari internal organisasi berupa kompetensi/kapabilitas/sumberdaya yang dimiliki organisasi, yang dapat digunakan sebagai 
alternatif untuk menangani ancaman. Perencanaan dari desa wisata Cabe di desa kabasiran mempunyai kekuatan khusus yang sudah teridentifikasi, yaitu:

1. Evia Abon Cabe sudah berproduksi secara rutin dan tidak kesulitan dalam memasarkan produknya secara offline dan on line, di dalam dan luar negeri, omset kurang lebih $\mathrm{Rp}$. 30 juta/ bulan

2. Evia Abon Cabe merupakan UKM yang berprestasi, mendapatkan banyak penghargaan dari pemerintah

3. Evia Abon Cabe sudah dipercaya lembaga swasta / BUMN sebagai mitra CSR untuk pemberdayaan masyarakat serta mendapatkan pendampingan dari BPPT untuk produksi dan manajemen usaha. Bahkan sudah menyusun BMC untuk Bon Cabe

4. Dari kerjasama dengan CSR ini juga sudah dibangun Kawasan "Kampung Cabe Jasindo" sebuah kawasan yang di dalamnya terdapat Galeri Evia, Dapur Evia (tempat produksi Abon Cabe), perumahan masyarkat yang menanam cabe.

5. Evia Abon Cabe sudah memiliki perijinan usaha PIRT, Sertifikat Halal sejak tahun 2014

6. Pengelola Evia Abon Cabe rutin melakukan pembinaan pemberdayaan ekonomi kepada masyarakat sekitar. Memiliki 30 UKM Binaan yang bernaung dalam Koperasi Cabe. Serta membina masyarakat (50 KK) dengan memberikan polybag cabe untuk dibudidayakan.

7. Pengelola Abon Cabe merupakan tokoh masyarakat yang rutin melakukan pembinaan terhadap masyarakat sehingga memiliki jaringan yang luas, hubungan yang baik dengan masyarakat, dan perangkat desa

8. Selain produksi Abon Cabe dibawah PT Evia Maju Bersama pengelola juga memiliki koperasi dengan nama Koperasi Cabe Merah untuk membina UKM masyarakat. Galeri Evia sebagai showroom produk dan Abon Cabe. Di kawasan Galeri Evia juga terdapat Café Manjaka yang dikelola oleh putra dari Bu Evie dan Pak Iman. Café ini buka pada sore hingga malam hari dan cukup ramai dikunjungi anak muda

9. Tergabung dalam komunitas IWAPI

10. Sering mengikuti bazar dan festival UKM baik mewakili pribadi maupun asosiasi

11. Di kawasan Galeri Evia, masih terdapat lahan yang bisa diolah dikelola untuk menjadi taman wisata

12. Abon Cabe sudah beberapa kali menjadi lokasi tujuan wisata edukasi UKM dan tanam cabe

b. Kelemahan (Weakness), merupakan situasi dari internal organisasi berupa kompetensi/kapabilitas/sumberdaya yang dimiliki organisasi, sulit digunakan sebagai alternatif untuk menangani kesempatan dan ancaman. Perencanaan dari desa wisata Cabe di desa kabasiran mempunyai kelemahan yang sudah teridentifikasi, yaitu:

1. Pengelola Abon Cabe memiliki banyak pekerjaan selain mengelola usaha Abon Cabe, juga mengelola sekolah dan pembinaan agama untuk masyarakat sekitar

2. Pencatatan keuangan usaha belum dilakukan sesuai dengan kaidah akuntansi, sehingga belum ada laporan keuangan yang rapi

3. Belum memiliki rencana usaha yang tertulis baik untuk pengembangan Abon Cabe maupun Desa Wisata

4. Belum memiliki SDM yang fokus untuk mengelola Desa Wisata

5. Belum terbentuk komunitas yang mewakili seluruh unsur masyarakat, yang nantinya akan terlibat secara intensif mulai dari perencanaan, pengelolaan dan pengembangan desa wisata

6. Belum ada pembinaan kepada masyarakat penerima polybag cabe yang berkenaan dengan teknis pertanian, untuk meningkatkan keterampilan masyarakat dalam budi daya cabe.

7. Produksi Cabe dari masyarakat hanya $2 \%$ dari seluruh kebutuhan produksi Abon Cabe, sehingga pengelola harus membeli cabe di pasar untuk memenuhi kebutuhan Abon Cabe 
8. Pembinaan UKM masyarakat sekitar dalam wadah Koperasi Cabe Merah yang dilakukan tim Abon Cabe belum dilakukan secara maksimal dalam hal marketing, pengelolaan keuangan usaha, dll

c. Peluang (Opportunity), merupakan situasi dari eksternal organisasi yang berpotensi menguntungkan. Seluruh organisasi yang berada salam satu industri sejenis umumnya akan merasa diuntungkan dengan adanya kondisi eksternal tersebut. Perencanaan dari desa wisata Cabe di desa kabasiran mempunyai peluang yang sudah teridentifikasi, yaitu:

1. Parung panjang memiliki destinasi wisata bukit Dago yang tidak jauh letaknya dari Galeri Evia. Bukit Dago terletak di Kelurahan Dago. Destinasi Wisata ini memiliki konsep destinasi wisata kekininan yaitu lokasi wisata terpadu,perkemahan, wahana permainan, area tracking motor pemandangan yang indah sekaligus lokasi yang instagramabel. Lokasi ini baru dikembangkan (kurang dari 1 tahun) namun sudah banyak pengunjungnya.

2. Belum banyak destinasi wisata, bahkan belum ada untuk destinasi wisata edukasi

3. Pembangunan desa melalui pengembangan kawasan wisata, saat ini menjadi tools yang banyak digunakan oleh pemerintah maupun swasta saat ini

4. Lokasi wisata berdekatan dengan stasiun kereta Parung Panjang, bisa ditempuh dengan ojek Rp 15.000 - Rp 20.000(ojek pangkalan)

5. Desa Kabasiran mengalami pembangunan yang pesat, terutama karena letaknya yang berdekatan dengan stasiun kereta Parung Panjang memiliki akses transportasi langsung ke ibu kota sehingga berfungsi sebagai daerah penyangga.

d. Ancaman (Threat), merupakan situasi dari eksternal organisasi yang berpotensi menimbulkan kesulitan. Seluruh organisasi yang berada salam satu industri sejenis umumnya akan merasa dirugikan dengan adanya kondisi eksternal tersebut. Perencanaan dari desa wisata Cabe di desa kabasiran mempunyai ancaman yang sudah teridentifikasi, yaitu:

1. Desa Kabasiran tidak memiliki potensi alam yang dapat dijadikan destinasi wisata.

2. Kondisi jalan di Parung Panjang banyak yang rusak, sebagian juga ada yang dibeton tapi ukuran jalan yg sempit (pas-pasan untuk kendaraan dua arah). Agak sulit untuk dilalui kendaraan besar seperti bus wisata

3. Desa Kabasiran saat ini sedang banyak dibangun perumahan mewah. Dan posisi perumahan-perumahan tersebut "mengepung" lokasi Kampung Cabe

4. Posisi Kampung Cabe, jika dilihat dari jalan akses dari Stasiun Parung Panjang, posisinya berada paling belakang dari Desa Kabasiran

5. Penduduk asli banyak yang masih hidup dalam kondisi kekurangan. Hal ini potensi menimbulkan kesenjangan ekonomi dan konflik social

6. Tingkat kecelakaan di jalan cukup tinggi, mengingat banyak truk pertambangan yang melewati jalan di Desa Kabasiran

7. Tingkat pendidikan penduduk yang rendah. Penduduk asli mayoritas lulusan SD/ SMP. Perlu usaha yang keras dan gigih untuk memotivasi masyarakat untuk bisa meningkatkan kualitas hidupnya

Dari paparan analisa SWOT di atas kemudian ditetapkan faktor-faktor terpenting untuk dimasukan ke dalam perhitungan matrik IFAS - EFAS. Perhitungan ini dapat dilihat pada Tabel 2 
ISSN NO. (PRINT) 2598-0823, (ONLINE) 2598-2893

Tabel 2. Perhitungan IFAS - EFAS Desa Wisata Kabasiran

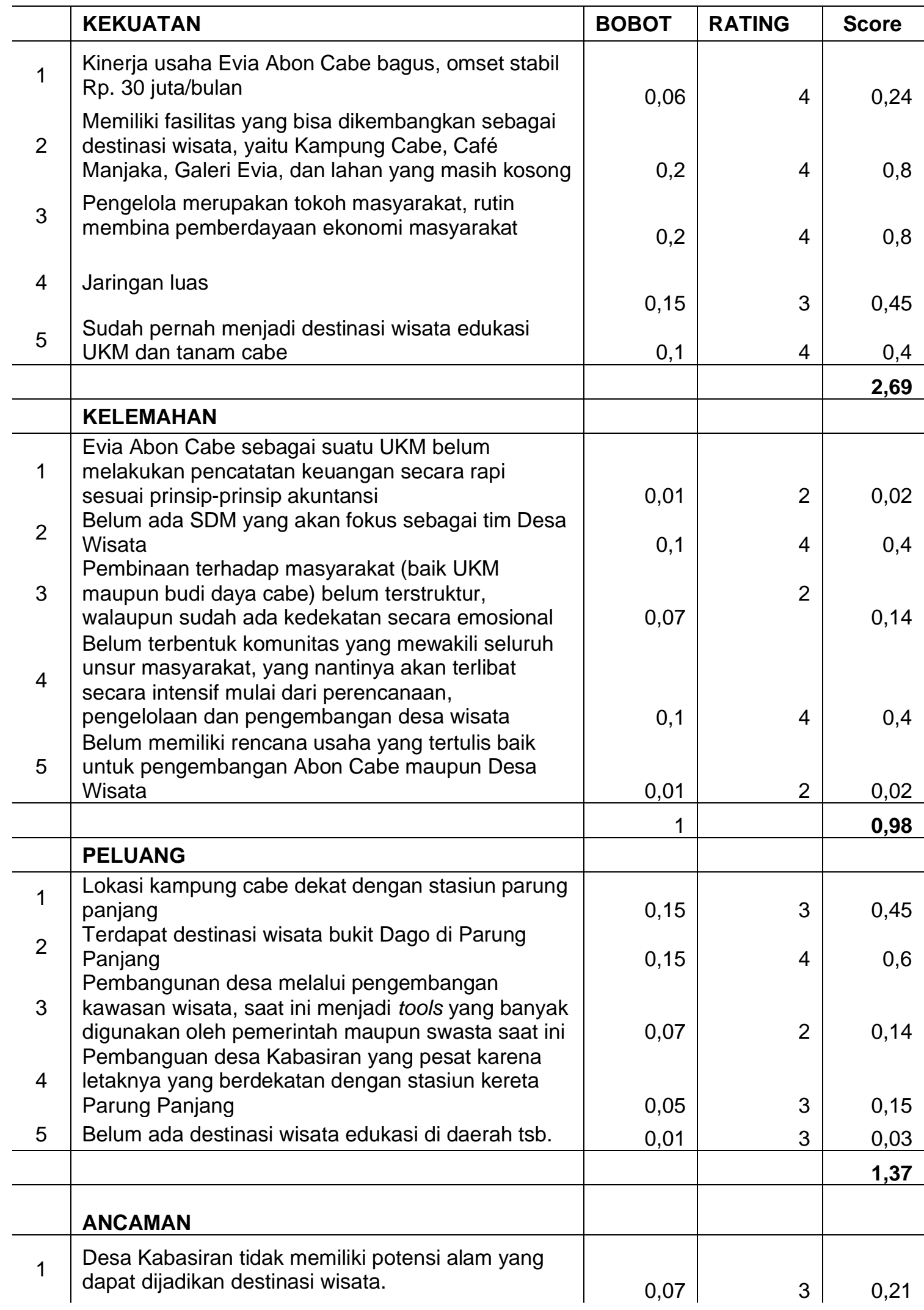




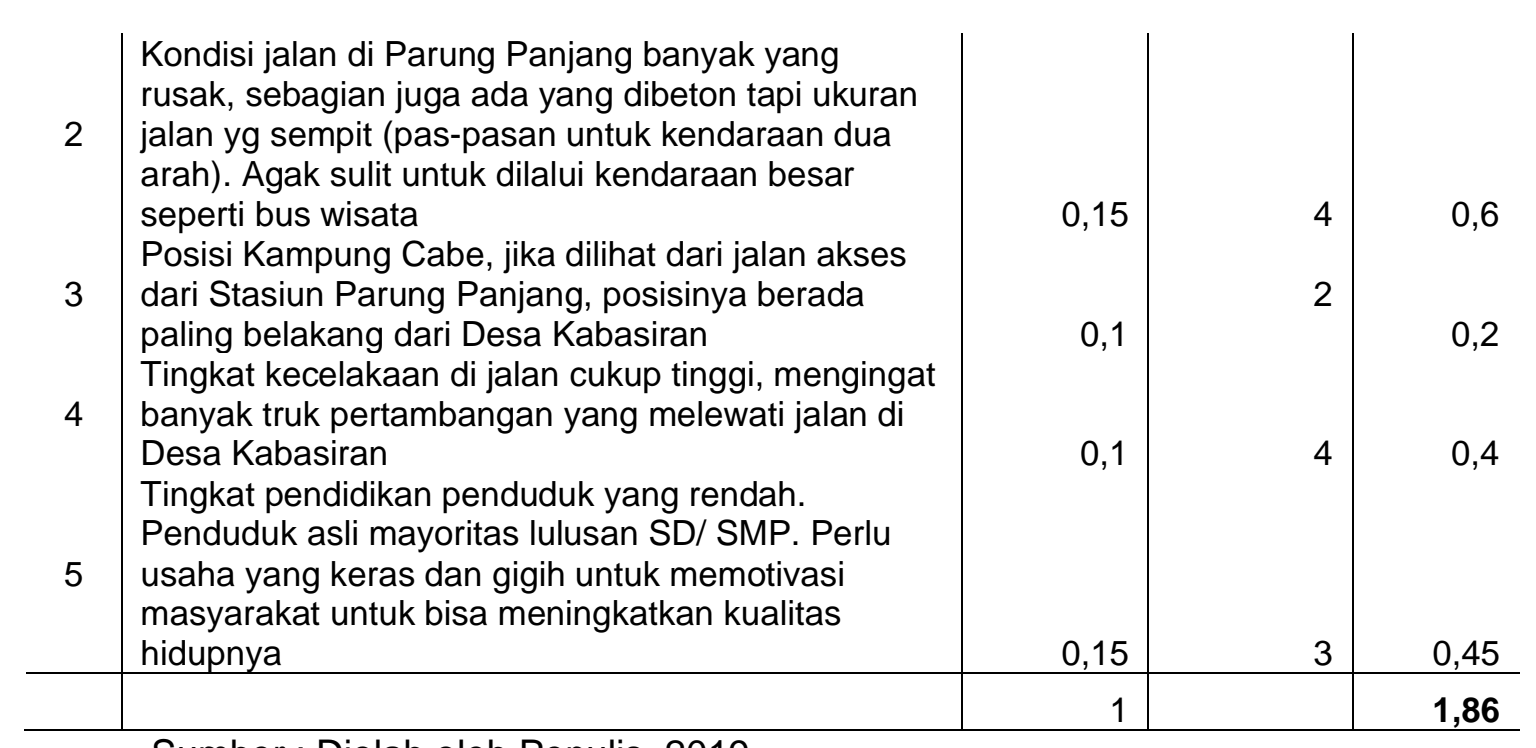

Sumber : Diolah oleh Penulis, 2019

Selanjutnya ditetapkan strategi berdasarkan analisa SWOT yang ada. Dimana strategi tersebut menggunakan kekuatan untuk memanfaatkan peluang dan mengatasi ancaman, serta meminimalkan kelemahan untuk memanfaatkan peluang dan menghindari ancaman. Strategi ini menjadi rekomendasi untuk dapat diimplementasikan di masa yang akan datang. Matriks SWOT dan kemungkinan solusi yang sesuai ditampilkan pada Tabel 3

Tabel 3. Matriks SWOT dan Kemungkinan Solusi

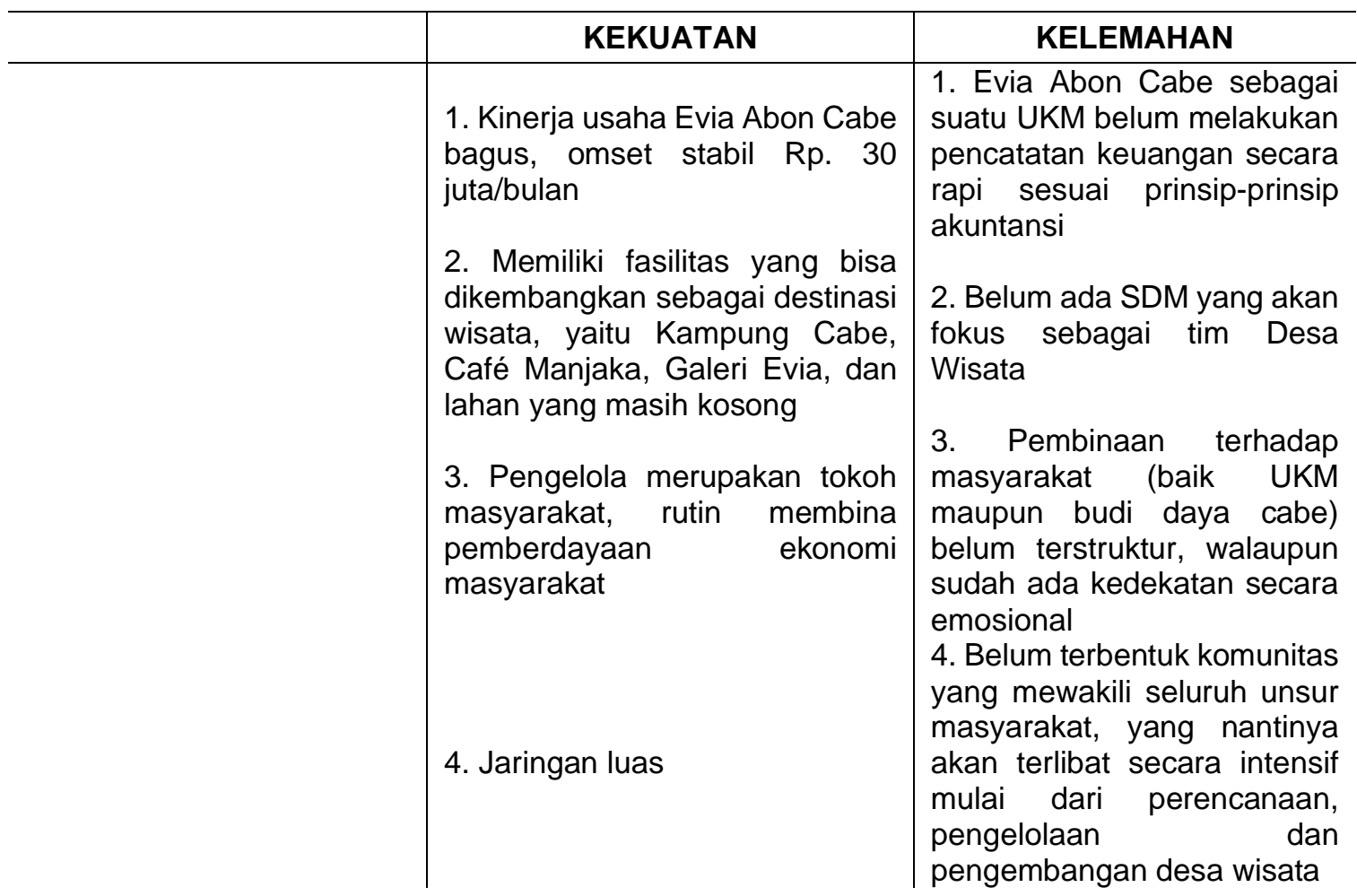




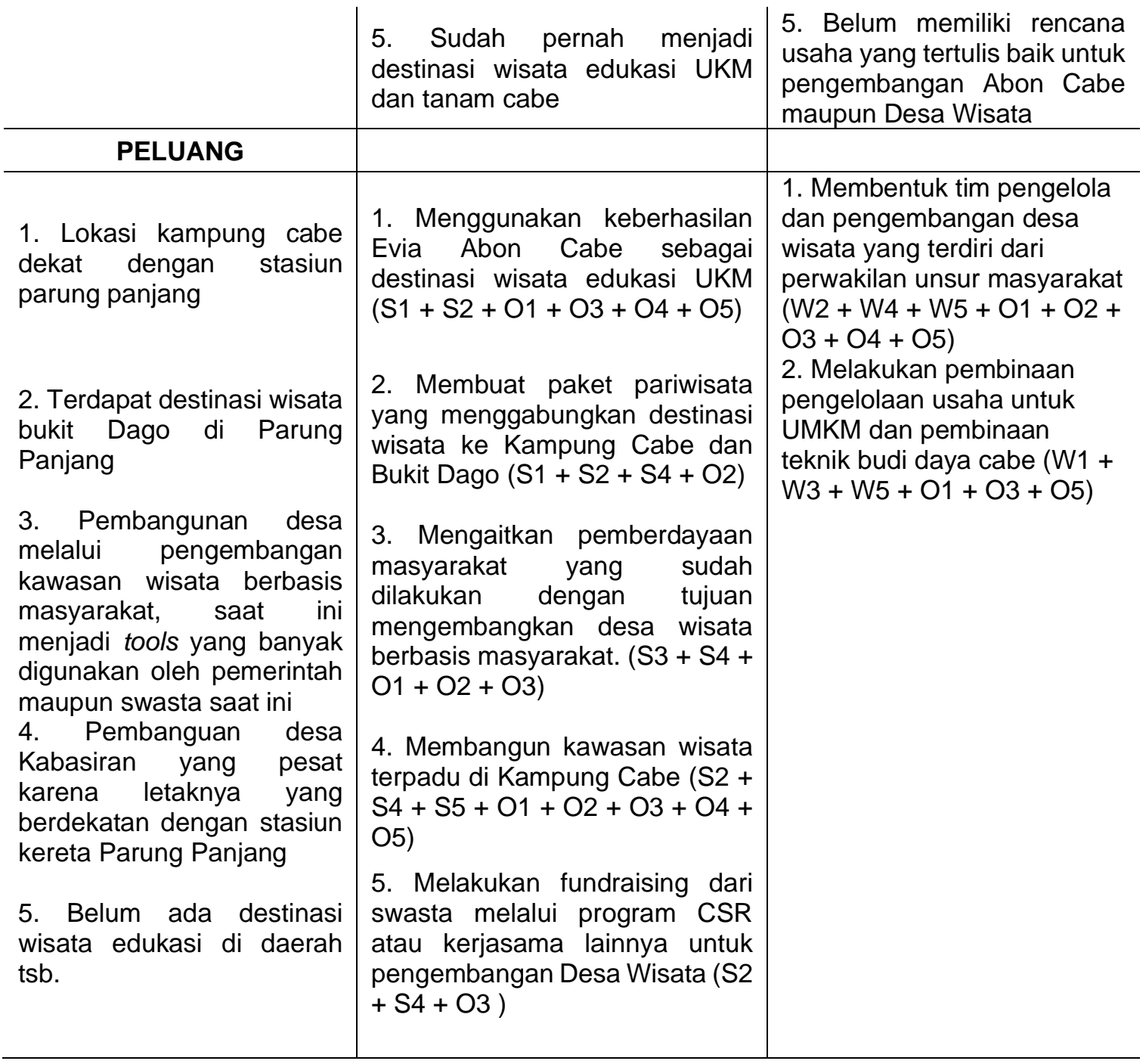

Sumber: data yang diolah

Pada Tabel 2 didapat hasil score akhir pada indikator kekuatan sebesar 2,69; pada indikator kelemahan memiliki score akhir sebesar 0,98; pada indikator peluang memiliki score akhir sebesar 1,37; dan pada indikator ancaman memiliki score akhir sebesar 1,86. Hasil dari score di empat indikator kemudian dilakukan perhitungan untuk menentukan titik kordinat $X$ dan $Y$. Untuk menghitung " $x$ " dilakukan perhitungan menggunakan rumus $(S-W) / 2$, dan untuk menghitung " $y$ " dilakukan perhitungan menggunakan rumus (O-T) / 2.

Dengan mengacu pada Tabel 2 dan rumus dalam menghitung titik kordinat $X$ dan $Y$, didapat nilai kordinat $X$ sebesar 0,855 dan nilai kordinat $Y$ sebesar $-0,245$. Hasil dari kordinat $X, Y$ dengan mengacu pada Gambar 6 analisis SWOT berada di posisi kuadran II. 


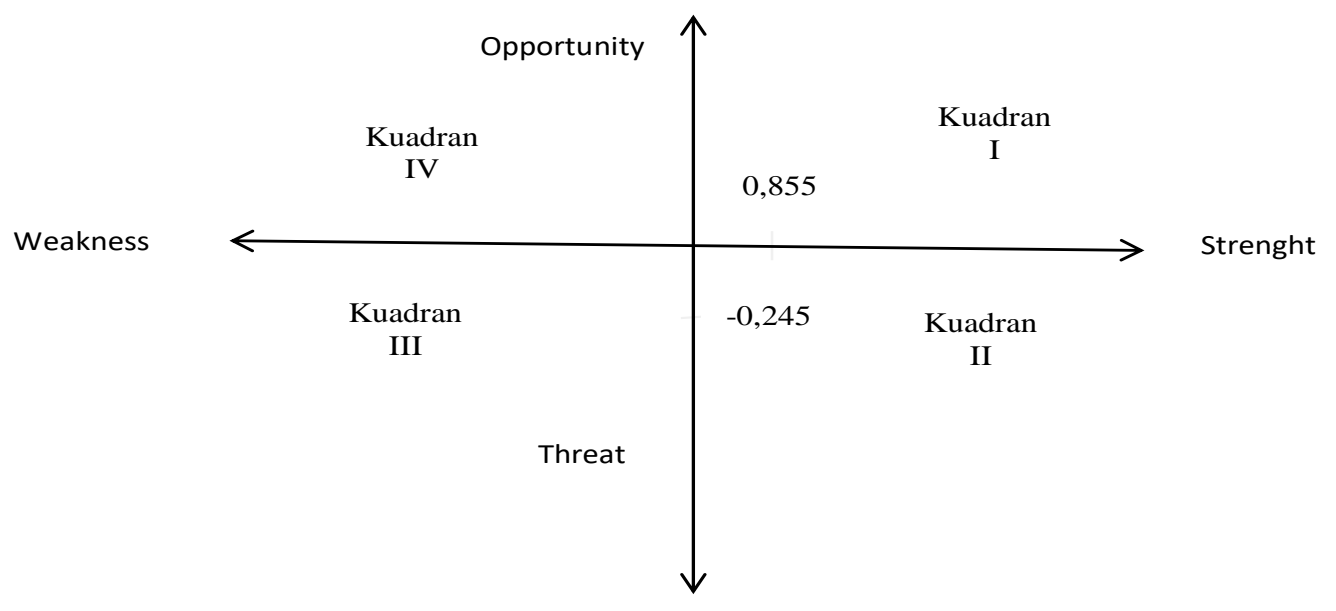

Gambar 6. Hasil analisis SWOT Desa Wisata Cabe Kabasiran

Berdasarkan Gambar 6, hasil analisis SWOT di Desa Wisata Kabasiran berada di Kuadran II, hal ini bisa disimpulkan, pengembangan dari Desa Wisata Kabasiran perlu mendukung strategi diversifikasi. Meskipun menghadapi berbagai ancaman, desa wisata ini masih memiliki kekuatan dari segi internal. Strategi yang harus diterapkan adalah menggunakan kekuatan untuk memanfaatkan peluang jangka panjang dengan cara strategi diversifikasi (produk / pasar) (Fredy, 2014;21). Dengan melihat kondisi di wilayah Desa Kabasiran yang memiliki kekuatan dan kelemahan, perlu adanya diversifikasi dari melakukan pembinaan kepada masyarakat Desa Kabasiran secara umum pada aspek yang menyeluruh, baik dari sisi pendidikan tentang informasi cara menanam cabe, pengolahan cabe menjadi variasi produk makanan yang unik (seperti coklat cabe, susu cabe keripik cabe, dll), kreativitas model menanam cabe yang unik, melatih masyarakat Desa Kabasiran dalam memberikan berbagai penyuluhan untuk para pengunjung yang ingin mendapatkan informasi tentang cabe, memberi pelatihan dari membuat kerajinan yang unik terkait cabe, ikut andil bekerjama dalam membangun akses jalan desa wisata cabe yang sangat terjangkau oleh pengunjung, bekerjasama dalam mempromosikan desa wisata cabe ke semua pengunjung melalui penyelenggaraan bazaar atau pasar rakyat, mengadakan pusat pelatihan menanam cabe untuk semua kalangan, adanya museum cabe terbesar, adanya produk hasil olahan cabe yang dipromosikan di media online dengan mengatasnamakan desa wisata cabe, keterlibatan dalam mempromosikan melalui media televisi dari adanya desa wisata cabe di wilayah Kabasiran Parung Panjang.

\section{E. KESIMPULAN}

Desa Wisata Cabe di Kabasiran perlu menerapkan strategi diversifikasi, karena berada dalam wilayah kekuatan dan ancaman. Diversifikasi harus dilakukan sebanyak mungkin, agar konsep pengembangan wisata ini bisa dikenal di masyarakat. Perlu adanya pembuatan edukasi, tempat wisata yang nyaman, dan produk olahan cabe yang unik. 


\section{DAFTAR PUSTAKA}

Affandi, Agus,. Et.al (2014). Modul Participatory Action Research (PAR) Untuk Pengorganisasian Masyarakat (Community Organizing). Surabaya. LPPM UIN Sunan Ampel.

Alam (2006). Ekonomi Untuk SMA dan MA. PT. Gelora Aksara Pratama. Jakarta

https://bogorkab.bps.go.id/statictable/2017/05/18/9/jumlah-penduduk-kabupaten-bogormenurut-kecamatan-.html.

https://bogorkab.bps.go.id Statistik Daerah Kecamatan Parung Panjang 2016. BPS Kabupaten Bogor 2016

Istiqomah, dan Andriyanto, Irsad. 2017. "Analisis SWOT dalam Pengembangan Bisnis (Studi pada Sentra Jenang di Desa Wisata Kaliputu Kudus)" Bisnis, Vol. 5 No. 2 Desember.

Marimin. (2004). Teknik dan Aplikasi Pengambilan keputusan Kriteria Majemuk, Grasindo, Jakarta.

Picard, Michel. (2006). Bali: Pariwisata Budaya dan Budaya Pariwisata, Kepustakaan Pupuler Gramedia, Jakarta.

Prastiwi, Susmita. Meirinawati, (2016). "Manajemen Strategis Dinas Kebudayaan dan Pariwisata Kabupaten Bojonegoro Dalam Mengembangkan Potensi Objek Wisata Edukasi Little Teksas Wonocolo". Publika Vol 4 No. 11

Rangkuti, Fredy. 2004. Analisis SWOT Teknik membedah Kasus Bisnis, PT. Gradia, Jakarta. Simanjuntak, Truman., Handini, Reton,. Riyanto, Sugeng. (2016) Karawang Dalam Lintasan Peradaban Pusat Jakarta.Penelitian Arkeologi Nasional

Sucahyowati, Hari. (2017). Pengantar Manajemen. Wilis

Sulistyadi, Yohanes; Eddyono, Fauziah, dan Entas, Derinta. (2019). Pariwisata Berkelanjutan dalam Perspektif Pariwisata Budaya di Taman Hutan Raya Banten, Uwais Inspirasi Indonesia, Ponorogo.

Tomal, Daniel. (2010) Action Research for Educator. United Kingdom. Rowman and Littlefield Education

Thomson. 2007. Pengantar Bisnis: Kontemporer, Edisi 11. 2007.

Ulung, Gagas. (2009). Liburan Murah Meriah di Jogja, PT. Gramedia Pustaka Utama, Jakarta.

Yoeti, Oka A. (2002). Ekonomi Pariwisata Introduksi, Informasi, dan Aplikasi, Kompas, Jakarta.

Zebua, Manhati, (2016). Inspirasi Pengembangan Pariwisata Daerah, Deepublish, Yogyakarta. 